\title{
Formation process of the incompatible martensite microstructure in a beta-titanium shape memory alloy
}

\author{
Tomonari Inamura $^{1,2^{*}}$, Masatoshi $\mathrm{Ii}^{3 * *}$, Masaki Tahara ${ }^{1,2}$ and Hideki Hosoda ${ }^{1,2}$ \\ ${ }^{1}$ Laboratory for Materials and Structures, Institute of Innovative Research, Tokyo \\ Institute of Technology, 4259 Nagatsutacho, Midori-ku, Yokohama, 226-8503, Japan \\ ${ }^{2}$ Laboratory for Future Interdisciplinary Research of Science and Technology (FIRST), \\ Institute of Innovative Research, Tokyo Institute of Technology, 4259 Nagatsutacho,
}

Midori-ku, Yokohama, 226-8503, Japan

${ }^{3}$ Graduate student, Tokyo Institute of Technology, 4259 Nagatsutacho, Midori-ku, Yokohama, 226-8503, Japan

*Corresponding author: Tomonari Inamura, email: inamura.t.aa@m.titech.ac.jp tel/fax: $+81-45-924-5058$

**Current affiliation: Mitsubishi Aluminum Co., Ltd., 85 Hiramatsu, Susono, Shizuoka, 410-1127, Japan

E-mail address

T. Inamura: inamura.t.aa@m.titech.ac.jp, M. Ii: masatoii@malco.co.jp,

M. Tahara: tahara.m.aa@m.titech.ac.jp, H. Hosoda: hosoda.h.aa@m.titech.ac.jp 


\section{Abstract}

The formation modes of habit plane variant (HV) clusters (HVCs) in a $\mathrm{Ti}-23 \mathrm{Nb}-3 \mathrm{Al}$ (mol\%) shape memory alloy were investigated by in situ optical microscopy with high-speed digital video camera. In addition to the kinematic compatibility condition, the nucleation mode and the interfacial energy between martensites were clearly shown to have critical roles. The $\mathrm{V}_{\mathrm{I}}$ cluster, which is formed by two HVs connected by a $\{111\}$ type I twin, predominated in the early stage of the martensitic transformation, and had a lower energy barrier to nucleation and growth than did the $\mathrm{V}_{\text {II }}$ cluster, which is formed by two HVs connected by a $<211>$ type II twin. Eighty percent of the $\mathrm{V}_{\text {I }}$ clusters were observed to form by paired nucleation or branching, in which the junction plane corresponds to the nucleation site of the relevant $\mathrm{HV}(\mathrm{s})$. In contrast, $\mathrm{V}_{\mathrm{II}}$ clusters formed as a result of collisions of HVs. Neither paired nucleation nor branching was observed for $\mathrm{V}_{\text {II }}$. $\mathrm{V}_{\mathrm{I}}$ nuclei rather than $\mathrm{V}_{\mathrm{II}}$ nuclei had a strong tendency to form, and this difference was not fully explained by the kinematic compatibility (KC) conditions. The junction planes formed by the collision of growing HVs should have larger deviation from the $\mathrm{KC}$ condition. The compatibility of the junction plane between HVs depends on the formation modes.

Keywords: in situ, self-accommodation, kinematic compatibility, crystallography 


\section{Introduction}

The martensite plate in most shape memory alloys (SMAs) has a habit plane that is an invariant plane as described by the phenomenological theory of martensite crystallography [1-3]. Such a martensite plate is conventionally called a "habit plane variant (HV)". The martensite microstructure consists of clustering HVs that reduce the net strain of the martensitic transformation in general [4]. A cluster of HVs is termed an "HV cluster (HVC)" in this study. The concept of self-accommodation or that of the plate group well explain the nature of the martensite microstructure [4]. However, understanding the connection between HVs is necessary for completely understanding the martensite microstructure and the thermomechanical properties of SMAs. Recent studies have shown that understanding the kinematic compatibility (KC) [5] between HVs is a key to understanding the martensite microstructure [6-17] and to controlling the properties of SMAs [18-21].

The continuity of a deformation at the interface between domain $\Omega_{\mathrm{A}}$ and $\Omega_{\mathrm{B}}$ with constant deformation gradients $\mathbf{A}$ and $\mathbf{B}$, respectively, can be maintained if Eq. 1 has a solution for $\mathbf{Q}, \mathbf{n}$, and $\mathbf{a}$ [22]. 
In Eq. 1, $\mathbf{Q}$ is a rigid body rotation, and $\mathbf{a}$ and $\mathbf{n}$ are vectors, with the vector $\mathbf{n}$ being that normal to the plane of the interface between $\Omega_{\mathrm{A}}$ and $\Omega_{\mathrm{B}}$. Eq. 1 corresponds to the $\mathrm{KC}$ condition for the HVC if $\Omega_{\mathrm{A}}$ and $\Omega_{\mathrm{B}}$ are HVs. The invariant plane condition at the habit plane is expressed by Eq. 1 assuming that QA is the deformation gradient of an HV and $\mathbf{B}=\mathbf{I}$, where $\mathbf{I}$ is the identity matrix representing the parent phase. For an HVC, A and B are the deformation gradients of the HVs and the rotation $\mathbf{Q}$ is the index of incompatibility of the connection between HVs. In general, SMAs, $\mathbf{Q} \neq \mathbf{I}$ and the junction plane between $\mathrm{HVs}$ maintains the $\mathrm{KC}$ condition when an $\mathrm{HV}$ is rotated by $\mathbf{Q}$; the rotation $\mathbf{Q}$ breaks the $\mathrm{KC}$ condition at the habit plane of the HV. Therefore, the incompatibility remains somewhere in the HVC for the case of $\mathbf{Q} \neq \mathbf{I}$ in general. Though the existence of the incompatibility is obvious, its location is not clear from geometrical considerations alone. Determining the location of the incompatibility is essential for understanding the nature of the martensite microstructure and the generation of lattice defects during cyclic actuation of SMAs.

In our previous work [9], the relationship between the frequency of formation of HVC and $\mathbf{Q}$ was investigated for a Ti-23Nb-3Al (mol\%) SMA using transmission 
electron microscopy (TEM). Figure 1 shows the typical morphologies and $\mathrm{KC}$ conditions of the HVCs of this alloy, which undergoes a $\beta$ (bcc) $-\alpha^{\prime \prime}$ (orthorhombic) martensitic transformation [23]. There is no lattice invariant deformation in the alloy because the middle eigenvalue of the lattice deformation is unity as reported in $\mathrm{Ti}_{50} \mathrm{Ni}_{39} \mathrm{Pd}_{11}$ alloy [21]. There are 10 types of HVCs in combination logic and only two HVCs that have very small $\mathbf{Q}$ are dominant in the alloy. The first type is termed a " $\mathrm{V}_{\mathrm{I}}$ cluster" and is formed by two HVs with the junction plane corresponding to the $K_{1}$ plane of the $\{111\}_{0}$ type I twin. The subscript "o" denotes $\alpha$ "-martensite. The second type is termed a " $\mathrm{V}_{\text {II }}$ cluster" with the junction plane corresponding to the $\mathrm{K}_{1}$ plane of the $<211>_{\mathrm{o}}$ type II twin. A theoretical analysis based on Eq. 1 showed the KC condition at the habit plane and junction plane to be conflicting each other in this alloy because $\mathbf{Q}$ $\neq \mathbf{I}$; the rotation angle of $\mathbf{Q}$ was calculated to be $0.69^{\circ}$ and $0.57^{\circ}$ for $\mathrm{V}_{\mathrm{I}}$ and $\mathrm{V}_{\mathrm{II}}$ clusters, respectively. The $\mathrm{KC}$ condition at the junction plane is satisfied when $\mathbf{Q}$ is applied to one $\mathrm{HV}$ and then the exact $\{111\}_{\mathrm{o}}$ type I twin orientation relationship (OR) and $<211>_{\mathrm{o}}$ type II twin OR appears across the junction plane for $V_{I}$ and $V_{\text {II }}$, respectively. Interestingly the location of the incompatibility was found to depend on the type of HVC in our previous study using precise Kikuchi line analysis [9]. For the $\mathrm{V}_{\mathrm{I}}$ cluster, $80 \%$ of the junction planes had a $\{111\}_{0}$ type I twin OR with angular deviation less than 
$0.1^{\circ}$ (less than the error of the orientation analysis by Kikuchi line). Here, the rotation $\mathbf{Q}$ acts and the $\mathrm{KC}$ at the junction plane is maintained at the expense of the $\mathrm{KC}$ at the habit plane. However, for the $\mathrm{V}_{\text {II }}$ cluster, $70 \%$ of the junction planes showed angular deviations greater than $0.4^{\circ}$ from the exact $<211>_{0}$ type II twin OR. Here, most of the junction planes were incompatible with maintaining the $\mathrm{KC}$ condition at the habit plane. Note that a microscopic observation of the fully developed microstructure did not seem to be able to explain the relatively high degree of maintaining $\mathrm{KC}$ at the junction plane of the $\mathrm{V}_{\mathrm{I}}$ cluster. Diversity of the microstructure in the vicinity of the junction plane has been considered to depend not only on the $\mathrm{KC}$ condition but also on the dynamic features of the formation of the microstructure [8]. Information obtained from a static observation of the fully transformed microstructure is, however, limited to the former factor.

Against this background, we focused on the dynamic process by which the martensite microstructure forms. The purpose of this study was to reveal this process and the origin of the location of incompatibility by in situ observation of the process of the martensitic transformation. According to these in situ observations, the $V_{I}$ and $V_{I I}$ clusters showed distinct differences in formation modes, and these differences were related to the differences in their locations of incompatibility. 


\section{Experimental procedures}

\subsection{Alloy}

Following our previous study [9], Ti-23mol\% $\mathrm{Nb}-3 \mathrm{~mol} \% \mathrm{Al}$ was selected for this study.

An ingot with a mass of about $10 \mathrm{~g}$ was fabricated from high-purity starting elements of

$\mathrm{Ti}(99.99 \%), \mathrm{Nb}(99.9 \%)$, and $\mathrm{Al}(99.99 \%)$ by Ar arc-melting with a non-consumable

W-electrode in an $\mathrm{Ar}-1 \% \mathrm{H}_{2}$ reducing atmosphere. Each ingot was arc-melted and then

flipped. This set of melting procedures was repeated five times to ensure homogeneity

of the product. The change in weight caused by arc-melting was less than $0.16 \mathrm{wt} \%$ and

was judged to be negligible, hence requiring no chemical analysis. The oxygen content

of the ingots previously fabricated by this method was less than 400 ppm by weight;

thus, we assumed that the oxygen content of the current ingot was similar. The ingot

was wrapped in a Ti foil, encapsulated in a quartz tube filled with an Ar atmosphere,

homogenized at $1273 \mathrm{~K}$ for $7.2 \mathrm{ks}$, and then quenched by breaking the quartz tube in

iced water. The martensitic transformation temperatures of the ingot were determined by

preliminary differential scanning calorimetry to be $M_{\mathrm{s}}=291 \mathrm{~K}, M_{\mathrm{f}}=249 \mathrm{~K}, A_{\mathrm{s}}=277 \mathrm{~K}$

and $A_{\mathrm{f}}=319 \mathrm{~K}$. The hysteresis, $\left(A_{\mathrm{f}}+A_{\mathrm{s}}-M_{\mathrm{f}}-M_{\mathrm{s}}\right) / 2$, was $28 \mathrm{~K}$ and seemed to be high, comparing with that of Ti-Ni-Pd with middle eigenvalue of unity [19]. However, 
according to that $\mathrm{Ti}-24 \mathrm{~mol} \% \mathrm{Nb}-3 \mathrm{~mol} \% \mathrm{Al}$ alloy has hysteresis of about $60 \mathrm{~K}$ and the middle eigenvalue is 0.999 [24], the hysteresis seems to be lowered in the present alloy by the middle eigenvalue of 1.0003 as described in the following.

Owing to that $A_{\mathrm{s}}<\mathrm{RT}<A_{\mathrm{f}}$, the lattice parameters of both phases were able to be determined directly at room temperature (RT, 298K) by a preliminary X-ray diffraction as $a_{\mathrm{b}}=328.0 \pm 0.5 \mathrm{pm}, a_{\mathrm{o}}=317.5 \pm 0.7 \mathrm{pm}, b_{\mathrm{o}}=479.0 \pm 0.1 \mathrm{pm}$, and $c_{\mathrm{o}}=464.0 \pm 0.1$ $\mathrm{pm}$, where the subscript $\mathrm{b}$ indicates the parent (bcc) phase. The eigenvalues of the lattice deformation with Au-Cd type lattice correspondence [25] were 0.9680, 1.0003 and 1.0326, with the middle eigenvalue being very close to unity at RT; no lattice-invariant deformation was observed by TEM $[19,23]$. $\mathbf{Q}$ of $\mathrm{V}_{\mathrm{I}}$ and $\mathrm{V}_{\text {II }}$ clusters are $0.64^{\circ}$ and $0.54^{\circ}$ for these lattice parameters, respectively. The thermal expansion coefficients of the parent and martensite phases were on the order of $10^{-5} / \mathrm{K}[26]$, so the effect of the thermal expansion was neglected for the temperature range used in this study. Following the results of numerical analysis in the previous study[9], the crystallographic quantities are calculated using the following lattice parameters that are in good agreement with the present value within the experimental error: $a_{\mathrm{b}}=328.061$ $\mathrm{pm}, a_{\mathrm{o}}=316.945 \mathrm{pm}, b_{\mathrm{o}}=479.321 \mathrm{pm}$, and $c_{\mathrm{o}}=463.948 \mathrm{pm}[9,23] . \quad$ The habit plane was approximately $\{755\}_{\mathrm{b}}$ and $12 \mathrm{HVs}$ were present. The lattice correspondence and the 
HV notation used here follows that of our previous study [9] and is summarized in Table 1; the habit plane normal $(\boldsymbol{p})$ and shape change direction $(\boldsymbol{d})$ are given in cubic coordinates.

\subsection{Specimen preparation and observation}

Figure 2 shows the procedure used to prepare the specimens. The specimens were cut by electrical discharge machining, polished by using emery paper and diamond paste (step 1) and finished by electropolishing in a solution of $6 \%$ perchloric acid, $35 \%$ butanol, and 59\% methanol (step 2). The best temperature for electropolishing with this solution was $228 \mathrm{~K}$ for the Ti- $23 \mathrm{~mol} \% \mathrm{Nb}-3 \mathrm{~mol} \% \mathrm{Al}$ alloy. According to the transformation temperatures, the specimen was in the martensite phase during the electropolishing and the surface was flattened in the martensite state (step 2). The surface relief due to the reverse transformation, therefore, appeared at RT after the electropolishing (step 3). The surface of the specimen was then finished by applying plasma etching (TENSEC, HORIBA) (step 4). The temperature of the specimen surface was higher than $A_{\mathrm{f}}$ during the plasma etching. The specimen surface could be flattened at the parent phase. A faint relief, however, remained even after the plasma etching. The crystallographic orientation of the specimen surface was identified by electron 
backscatter diffraction (EBSD) analysis using a field-emission gun-type scanning electron microscope (S-4300SE, Hitachi) equipped with an EBSD detector (e-Flash ${ }^{1000}$, Bruker).

In situ differential interference contrast microscopy was performed using a digital microscope (VHX-100F, Keyence) equipped with a high-speed digital video camera (VW-9000, Keyence), a data collection system (NR-600, Keyence) and a temperature-controlled chamber (LMT-600, Collet Kogyo). The specimen was attached to a specimen stage made of pure silver with heat-conducting grease. Two K-type thermocouples were used. The thermocouple on the specimen stage was used for controlling the temperature, and the other thermocouple on the side face of the specimen was used for measuring the actual temperature of the specimen. The specimen was first heated to $323 \mathrm{~K}$ and then cooled to $223 \mathrm{~K}$ at a cooling rate of $5 \mathrm{~K} / \mathrm{min}$ in a near-vacuum condition of $<3.0 \times 10^{-3} \mathrm{~Pa}$. The HVs were identified by single-trace analysis of the surface reliefs that resulted from the martensitic transformation.

\section{Results}

The observed area was located at about the center of a coarse $\beta$-grain of several millimeters in diameter. The surface normal of the observed area was determined to be 
$\left[\begin{array}{lll}88 & 40 & 100\end{array}\right]_{\mathrm{b}}$ by the preliminary EBSD analysis. Figure 3 shows a stereographic projection of $\boldsymbol{p}$ and $\boldsymbol{d}$ viewed from this surface normal and was used for the trace analysis of the micrographs.

\subsection{Overview of the martensitic transformation}

An overview of the martensitic transformation upon cooling is shown in Figs. 4(a)-(e). The temperature dependence of the formation frequency of HVCs is summarized in Fig. 4(f). Above $308 \mathrm{~K}$ (Fig. 4(a)), the specimen was fully in the parent phase but some traces that had not been removed completely in step 4 of Fig. 2 were seen. At about $303 \mathrm{~K}$, martensite plates started to form in the interior of the grain. Each HV nucleated as a thin plate growing along the habit plane trace with a propagation velocity of $10^{-2} \mathrm{~m} / \mathrm{s}$ on average and then thickened consecutively. Isolated martensite plates were uncommon; most of the HVs formed pairs. The formation of paired martensite HVs is effective for reducing net strain and is common in the martensitic transformation [4]. Some martensite plates that appeared to be isolated in the image were possibly paired with a specific HV inside the specimen.

Only $\mathrm{V}_{\mathrm{I}}$ clusters appeared in the early stage of the transformation, as indicated by the arrow pointing to the HV notation in Fig. 4(b). A triangle (T) cluster was 
observed, as indicated by the triple-headed arrow of Fig. 4(b), but is categorized as a $V_{I}$ cluster here, because it was determined to be a derivative of $V_{I}$ as demonstrated in the following section.

$\mathrm{V}_{\mathrm{II}}$ clusters appeared upon further cooling, as indicated by the double-headed arrows in Figs. 4(c) and (d). The formation frequency of this type of cluster was, however, lower than that of the $\mathrm{V}_{\mathrm{I}}$ cluster. The formation of the $\mathrm{V}_{\mathrm{II}}$ cluster was significantly activated in the middle stage of the transformation, as seen in Fig. 4(f). The martensite microstructure became well developed with further cooling, and Fig. 4(e) shows the martensite microstructure at $223 \mathrm{~K}$, which was the lowest temperature investigated in this experiment. As the transformation proceeded, the HVs became smaller because the untransformed parent phase became divided by larger HVs.

The numbers of HVCs below $M_{\mathrm{f}}$ that we identified are summarized in Fig. 5. Tiny HVs that were not confidently identified were not included in the statistics. The black cells and the gray cells in Fig. 5 indicate $V_{I}$ and $V_{I I}$ clusters, respectively; the numbers of the observed HVCs are shown in the corresponding cells. The total number of the identified HVCs was 150.

The identified HV types were 1(+), 2(+), 3(+), 4(+), 5(+) and 6(-), whereas 1(-), 2(-), 3(-), 4(-), 5(-) and 6(+) were not detected even below $M_{\mathrm{f}}$. Figure 3 explains why 
some HVs were not observed. These undetected HVs would have habit planes nearly parallel to the surface normal or shape change directions almost perpendicular to the surface normal. The contrast of the interference image was weakened in these HVs because the slope of the surface relief on the specimen surface became flat. We therefore suggest that the undetected HVs formed in the area resembling the untransformed parent phase in Fig. 4(e). This is the reason why some parts of the specimen appeared at first glance as if they were untransformed even at $223 \mathrm{~K}$ and why the fractions of $V_{I}$ and $V_{I I}$ determined in the present study were very different from the results in our previous study using TEM [9]. The shape change directions of the observed HVs were close to the surface normal and the transformation strains can be relaxed at the surface. This surface effect may have affected the fraction of the HVs in the present study [27]. Therefore, the fractions of $\mathrm{HVs}$ that formed $\mathrm{V}_{\mathrm{I}}$ and $\mathrm{V}_{\text {II }}$ were not reliable here, and only the processes of HVC formation are considered in the following sections.

\section{2. $V_{I}$ cluster formation modes}

The $V_{I}$ cluster formation modes were analyzed in detail. There were three such modes of formation. The first one involved the simultaneous formation or "paired 
nucleation" of HVs from their junction plane. Figure 6(a) shows snapshots of the paired nucleations for $2(+)$ and $6(-)$. This type of formation was detected only at the early stage of the transformation and $4 \%$ of the $V_{I}$ clusters were formed by this process. The second mode involved the "branching" of an HV from a pre-existing HV and was the major process. This process is shown in Fig. 6(b), where the nucleation of a 6(-) HV from a pre-existing 2(+) HV was captured. This type of formation mode was observed for all temperatures tested and $75 \%$ of the $\mathrm{V}_{\mathrm{I}}$ clusters formed by this process. The third mode involved the "collision" of two growing HVs as shown in Fig. 6(c) for 1(+) and 3(+) HVs. The fraction of $V_{I}$ clusters formed by such collisions was about $20 \%$. It should be noted that $80 \%$ of the $\mathrm{V}_{\mathrm{I}}$ clusters formed by paired nucleation or branching, in which the junction plane corresponded to the nucleation site of the relevant $\mathrm{HV}(\mathrm{s})$.

The process used to form of a T cluster was also captured, as shown in Fig. 7. A $\mathrm{V}_{\mathrm{I}}$ cluster first formed and then the third HV formed consecutively; this was the only formation process observed. The simultaneous formation of the three HVs was not observed. The T cluster shown in Fig. 7 was formed from 1(+), 3(+), and 5(+) HVs that were mutually related by the $\{111\}_{0}$ type I twin OR as determined by our previous study [9]. First, a $\mathrm{V}_{\mathrm{I}}$ cluster was formed from $1(+)$ and $5(+) \mathrm{HVs}$ and then a $3(+) \mathrm{HV}$ was additionally formed by branching from the $1(+) \mathrm{HV}$. The 3(+) HV grew and collided 
with a $5(+) \mathrm{HV}$, leading to the formation of a closed triangle. The $\mathrm{T}$ cluster was, therefore, regarded as a derivative of the $\mathrm{V}_{\mathrm{I}}$ cluster. The increase in the HV thickness involved the growth being directed toward the interior of the triangle, as depicted in the insets in Fig. 7. The center of the T cluster, however, was not filled by the three HVs. This was due to the presence of a partial wedge disclination [9]. The detailed structure at the center of the T-cluster could not be identified in the present optical microscopy experiment.

\section{3. $V_{\text {II }}$ cluster formation modes}

Two distinct modes of formation were observed for the $\mathrm{V}_{\mathrm{II}}$ cluster. One was the "collision" of growing HVs as observed for $\mathrm{V}_{\mathrm{I}}$ clusters and the other was the "reflection" of a growing $\mathrm{HV}$ at a point of collision with another HV. Figure 8(a) shows a formation of a $\mathrm{V}_{\mathrm{II}}$ cluster resulting from the collision mode. Two HVs, namely, 2(+) and 5(+), were observed to grow in the directions indicated by the arrows. These two HVs eventually collided and then formed a $V_{\text {II }}$ cluster. Fifty-three percent of the $V_{\text {II }}$ clusters formed in this way. The formation of $\mathrm{V}_{\mathrm{II}}$ by the "reflection" mode is shown in Fig. 8(b). A 2(+) HV was observed growing along the habit plane trace as indicated by the arrow, and collided with another HV. A new, 5(+) HV nucleated at the point of the collision and 
started growing in the opposite direction, resembling a reflection (see the third frame of Fig. 8(b)). Forty-seven percent of the $\mathrm{V}_{\text {II }}$ clusters were formed by this process. It should be emphasized that paired nucleation and branching, which were commonly observed modes for forming $V_{I}$ clusters, were never observed for formation of a $V_{\text {II }}$ cluster.

\subsection{Relationship between the magnitudes of the energy barriers to the formation of $V_{I}$} and $V_{I I}$

Figure 9 summarizes the temperature dependence of the frequency of each formation process for $V_{I}$ and $V_{I I}$ clusters upon cooling. Only $V_{I}$ formed in the early stage of the transformation $(308 \mathrm{~K}$ to $303 \mathrm{~K})$. The relationship between the magnitudes of the energy barriers to the formation of the HVC clusters was determined directly from the experimental results. In general, martensitic transformations require supercooling because the energy barrier that is the sum of the elastic energy and dissipation energy must be overcome by the accumulated Gibbs energy [28]. The lower the temperature, the higher is the accumulated Gibbs energy, and when the temperature is below the equilibrium temperature, $T_{0}$, the Gibbs energies of the parent and martensite are equal. In other words, the martensite plate or HVC that appears just below $M_{\mathrm{s}}$ has the lowest energy barrier to its nucleation and growth. Therefore, based on the results shown in Fig. 
9, the $V_{I}$ cluster was determined to be more energetically favored than the $V_{I I}$ cluster. Note that neither the nucleation nor growth of an HV from the junction plane was ever observed for $\mathrm{V}_{\text {III }}$. The preferential formation of a specific $\mathrm{HV}$ cluster has also been observed in situ for the martensitic transformation in Ti-Ni [29]. The present experimental results taken together revealed the nucleation of the martensite from the $V_{I}$ junction plane, that is, the $K_{1}$ plane of $\{111\}_{0}$ type I twin, to be energetically favored, and the paired nucleation and branching modes of formation to then be significant for only the $\mathrm{V}_{\mathrm{I}}$ cluster. The $\mathrm{V}_{\mathrm{II}}$ cluster was clearly determined to be a product of the collisions of HVs growing as parts of $\mathrm{V}_{\mathrm{I}}$ clusters, whereas the details of the reflection mode remain to be determined.

\section{Discussion}

\subsection{Origin of the incompatible junction plane}

As mentioned in the Introduction, Fig. 1 shows the fractions of the $V_{I}$ and $V_{\text {II }}$ clusters containing incompatible junction planes. Compatible junction planes were found in about $80 \%$ of the $\mathrm{V}_{\mathrm{I}}$ clusters, whereas about $70 \%$ of $\mathrm{V}_{\mathrm{II}}$ clusters had incompatible

junction plane. A concurrence between the fractions of the clusters displaying incompatible junction planes (Fig. 1) and the fractions of the clusters formed by specific 
modes was revealed by the present study. Figure 10 summarizes the fractions of $V_{I}$ and $\mathrm{V}_{\text {II }}$ clusters formed by each mode. Approximately $80 \%$ of the $\mathrm{V}_{\mathrm{I}}$ clusters were formed by paired nucleation (PN) or branching, in which the junction plane corresponded to the nucleation site of the relevant $\mathrm{HV}(\mathrm{s})$. This fraction matches the fraction of the $\mathrm{V}_{\mathrm{I}}$ clusters containing compatible junction planes (Fig. 1). On the other hand, more than $50 \%$ of the $\mathrm{V}_{\mathrm{II}}$ clusters were formed by collisions (Fig. 10), and this value approximately corresponds to the fraction of $\mathrm{V}_{\text {II }}$ clusters containing incompatible junction planes. By assuming that the exact $\{111\}_{0}$ type I twin OR yielded the lowest energy for the HVCs, this concurrence can be interpreted as follows without any contradiction to the present experimental results. Figure 11 shows the relationship between formation mode and location of the incompatibility. The formation of $V_{I}$ clusters by paired nucleation or branching requires the $\{111\}_{0}$ type I twin relationship to be exactly held at the junction plane by breaking the compatibility of habit planes around the junction plane. As a result, the fraction of $V_{I}$ clusters with compatible junction planes corresponded to the sum of the fractions of $\mathrm{V}_{\mathrm{I}}$ clusters formed by paired nucleation and branching. On the other hand, the martensite plates maintain compatible habit planes during their growth; and the junction planes formed by collisions must be incompatible in this case because of the competition between the KCs at the habit plane 
and junction plane. The fraction of the clusters with incompatible interfaces and the fraction of the clusters formed by collisions were, therefore, almost the same.

Delville et al. [21] pointed out that HVs collide each other and their junction planes form relevant twin boundary after the action of $\mathbf{Q}$ in $\mathrm{Ti}_{50} \mathrm{Ni}_{39} \mathrm{Pd}_{11}$ alloy, which has middle eigenvalue of unity. In their work, however, the formation processes of the junction planes and the precise analysis of the incompatibility at twin boundary were not analyzed. In the case where the middle eigenvalue is not unity, diversity of the microstructure has been observed in the vicinity of the junction planes between internally twinned HVs in several alloys $[7,8,11,13,17]$. Tapering and bending of the internal twin of minor volume fraction and the rotation of lattice have been observed around the junction planes in $\mathrm{Ni}_{65} \mathrm{Al}_{35}[7,8,11,17]$. These microstructures are considered to relax the local incompatibility that is enforced by the coalescence or collision of growing $\mathrm{HVs}[7,8,11,17]$. In the present case, the local incompatibility at junction plane of $\mathrm{V}_{\mathrm{II}}$ is expected to be accommodated by interfacial dislocations or local rotation of lattice in the vicinity of the junction plane because there is no internal twin to tune the total deformation of the HVs. According to the present results, it is emphasized that not only the coalescence but also the nucleation process of $\mathrm{HV}$ affects the character of the junction planes. An in-situ observation together with a precise 
orientation analysis must be able to distinguish the compatible and incompatible junction planes and their origin that is related to the dynamical process of the transformation in other alloys.

\subsection{Preferential nucleation of $V_{I}$}

It is quite interesting that compared to the $V_{\text {II }}$ cluster, the $V_{I}$ cluster more easily nucleated despite its slightly larger rotation $\mathbf{Q}$ to maintain the $\mathrm{KC}$ condition at the junction plane as summarized in Fig. 1. This study clearly demonstrated that the $\mathrm{KC}$ condition does not fully describe the variant selection rule in the nucleation stage. A similar situation was shown for Ti-Ni [29]. The preferential V-shaped cluster can satisfy the $\mathrm{KC}$ condition and the $\{\overline{1} 11\}$ type I twin orientation at the junction plane simultaneously and its $\mathbf{Q}$ is not the smallest one [14]. An explanation is the interfacial energy of the $<211>_{\mathrm{o}}$ type II twin boundary being much higher than that of the $\{111\}_{\mathrm{o}}$ type I twin, and the paired nucleation of the $\mathrm{V}_{\mathrm{II}}$ cluster being virtually impossible despite the rotation $\mathbf{Q}$ being smaller than that of $\mathrm{V}_{\mathrm{I}}$. This explanation is based on the general relationship between particle size and energy, namely, the smaller the particle, the higher the ratio of its interfacial energy to its total energy [30]. Our previous study[9] found the values of $\mathbf{Q}$ for the $\mathrm{V}_{\mathrm{I}}\left(0.69^{\circ}\right)$ and $\mathrm{V}_{\text {II }}\left(0.57^{\circ}\right)$ clusters to be an order 
of magnitude smaller than those for the other HVCs. $\mathbf{Q}$ is an indicator of the incompatibility that arises upon the formation of an $\mathrm{HVC}$ and is related to the elastic strain energy. The preferential formation of $V_{I}$ and $V_{I I}$ clusters rather than the other HVCs is, therefore, well explained by $\mathbf{Q}$ without considering any other energy such as interfacial energy as demonstrated in our previous study [9]. However, interfacial energy may be comparable to the difference between elastic strain energy of $V_{I}$ and $V_{I I}$ and may have affected the energy balance of the nuclei of $V_{I}$ and $V_{\text {II }}$ in this study.

An alternative explanation, one based on the dynamic motion of the atoms, may also be plausible. The directions of displacement, $\boldsymbol{d}$, for the HVs forming the $\mathrm{V}_{\mathrm{I}}$ cluster were found to be very similar, and to cluster around $<111>_{b}$, as seen in Fig. 3; for example, see $\boldsymbol{d}_{1(+)}, \boldsymbol{d}_{3(+)}$, and $\boldsymbol{d}_{5(+)}$. This finding suggested a cooperative motion of atoms at the $\mathrm{V}_{\mathrm{I}}$ junction plane. On the other hand, the directions of displacement for the HVs forming the $\mathrm{V}_{\text {II }}$ cluster were found to differ by $120^{\circ}$; see $\boldsymbol{d}_{1(+)}$ and $\boldsymbol{d}_{4(-)}$ in Fig. 3. That is, the projected displacements of atoms on the $\mathrm{V}_{\text {II }}$ junction plane varied considerably, suggesting the cooperative motion of atoms here to be impossible. Such a considerably greater cooperativity of the motions of the atoms at the $\mathrm{V}_{\mathrm{I}}$ rather than $\mathrm{V}_{\mathrm{II}}$ junction plane would thus also explain the preferred nucleation of the $V_{I}$ cluster.

Though the nature of the preference for $\mathrm{V}_{\mathrm{I}}$ nucleation is not clear, it is evident 
that there is a strong tendency to form $\mathrm{V}_{\mathrm{I}}$ rather than $\mathrm{V}_{\mathrm{II}}$ in the nucleation stage and that this preference is not fully explained by a simple evaluation of $\mathbf{Q}$. The location of incompatibility is governed by the formation sequence of the $\mathrm{HVC}$, namely nucleation or collision, and this is another striking finding in this study.

\section{Conclusions}

The modes of formation of the HVCs in a Ti-23Nb-3Al (mol\%) SMA was investigated by using in situ optical microscopy, and the following conclusions were obtained for this alloy.

1. The $V_{I}$ cluster is the dominant type in the early stage of the martensite transformation of this alloy and has a lower energy barrier to nucleation and growth than does the $\mathrm{V}_{\mathrm{II}}$ cluster, despite a larger incompatibility at junction planes.

2. A T cluster of this alloy can be formed by additional formation of a specific HV onto a pre-existing $\mathrm{V}_{\mathrm{I}}$ cluster, and is hence a derivative of $\mathrm{V}_{\mathrm{I}}$.

3. A considerable majority of $V_{I}$ clusters in this alloy form by paired nucleation or 
branching, in which the junction plane corresponds to the nucleation site of the relevant $\mathrm{HV}(\mathrm{s})$. In contrast, $\mathrm{V}_{\mathrm{II}}$ clusters primarily form as a result of collisions of HVs. (Neither paired nucleation nor branching was observed for $\mathrm{V}_{\text {II. }}$ ) There is a stronger tendency to form $\mathrm{V}_{\mathrm{I}}$ nuclei than $\mathrm{V}_{\mathrm{II}}$ nuclei, and this difference is not fully a result of $\mathrm{KC}$ conditions. The effect of interfacial energy is a critical factor in the selection of the nucleation mode.

4. The junction planes formed by the collisions of growing HVs are thought to have larger deviation from the $\mathrm{KC}$ condition. The compatibility of the junction plane depends on the formation modes.

\section{Acknowledgements}

This work was partially supported by the Advanced Low-Carbon Technology Research and Development Program (JY240121) from the Japan Science and Technology Agency, Grant-in-Aid of Scientific Research (S: 26220907 and B:15H04143) and Grant-in-Aid for Young Scientists (B: 26870194) from the Japan Society for the Promotion of Science. 


\section{References}

[1] M.S. Wechsler, D.S. Lieberman, T.A. Read. On the Theory of the Formation of Martensite, Transactions AIME 197 (1953) 1503-1515.

[2] J.S. Bowles, J.K. Mackenzie. The Crystallography of Martensite Transformations I, Acta Metall 2 (1954) 129-137.

[3] J.K. Mackenzie, J.S. Bowles. The Crystallography of Martensite Transformations II, Acta Metall 2 (1954) 138-147.

[4] K. Otsuka, C.M. Wayman. Shape Memory Materials, Cambridge University Press, 1999.

[5] J.M. Ball, R.D. James. Fine phase mixtures as minimizers of energy, Archive for Rational Mechanics and Analysis 100 (1987) 13-52.

[6] X. Barandlaud, D. Delpueyo, M. Grediac, G. Zanzotto. Almost compatible microstrcture of martensite, Acta Mater 58 (2010) 4559-4577.

[7] J.M. Ball, D. Schryvers. The analysis of macrotwins in NiAl martensite, Journal de physique IV France 112 (2003) 159-162.

[8] P. Boullay, D. Schryvers, J.M. Ball. Nano-structures at martensite macrotwin interfaces in Ni65Al35, Acta Mater 51 (2003) 1421-1436.

[9] T. Inamura, H. Hosoda, S. Miyazaki. Incompatibility and preferred morphology in the self-accommodation microstructure of B-titanium shape memory alloy, Philos Mag 93 (2013) 618-634.

[10] T. Teramoto, M. Tahara, H. Hosoda, T. Inamura. Compatibility at Junction Planes between Habit Plane Variants with Internal Twin in Ti-Ni-Pd Shape Memory Alloy, Materials Transactions 57 (2016) 233-240.

[11] T. Inamura, H. Hosoda. Crystallography of Martensite in TiAu Shape Memory Alloy, Metallurgical and Materials Transactions A 42 (2010) 111-120.

[12] M. Nishida, T. Nishiura, H. Kawano, T. Inamura. Self-accommodation of B19' martensite in Ti-Ni shape memory alloys - Part I. Morphological and crystallographic studies of the variant selection rule, Philos Mag 92 (2012) 2215-2233.

[13] M. Nishida, E. Okunishi, T. Nishiura, H. Kawano, T. Inamura, S. Ii, T. Hara. Self-accommodation of $\mathrm{B}^{1} 9^{\prime}$ martensite in $\mathrm{Ti}-\mathrm{Ni}$ shape memory alloys - Part II. Characteristic interface structures between habit plane variants, Philos Mag 92 (2012) 2234-2246.

[14] T. Inamura, T. Nishiura, H. Kawano, H. Hosoda, M. Nishida. Self-accommodation of B19' martensite in Ti-Ni shape memory alloys. Part III. Analysis of habit plane variant clusters by the geometrically nonlinear theory, Philos Mag 92 (2012) 2247-2263.

[15] T. Waitz. The self-accommodated morphology of martensite in nanocrystalline NiTi 
shape memory alloys, Acta Mater 53 (2005) 2273-2283.

[16] X. Chen, V. Srivastava, V. Dabade, R.D. James. Study of the cofactor conditions: Conditions of supercompatibility between phases, J Mech Phys Solids 61 (2013) 2566-2587.

[17] P. Boullay, D. Schryvers, R. Kohn. Bending martensite needles in Ni65Al35 investigated by two-dimensional elasticity and high-resolution transmission electron microscopy, Physical Review B 64 (2001).

[18] Y. Song, X. Chen, V. Dabade, T.W. Shield, R.D. James. Enhanced reversibility and unusual microstructure of a phase-transforming material, Nature 502 (2013) 85-88.

[19] J. Cui, Y.S. Chu, O.O. Famodu, Y. Furuya, J. Hattrick-Simpers, R.D. James, A. Ludwig, S. Thienhaus, M. Wuttig, Z. Zhang, I. Takeuchi. Combinatorial search of thermoelastic shape-memory alloys with extremely small hysteresis width, Nat Mater 5 (2006) 286-290.

[20] C. Chluba, W. Ge, R. Lima de Miranda, J. Strobel, L. Kienle, E. Quandt, M. Wuttig. Ultralow-fatigue shape memory alloy films, Science 348 (2015) 1004-1007.

[21] R. Delville, S. Kasinathan, Z. Zhang, J.V. Humbeeck, R.D. James, D. Schryvers. Transmission electron microscopy study of phase compatibility in low hysteresis shape memory alloys, Philos Mag 90 (2010) 177-195.

[22] K. Bhattacharya. Microstructure of Martensite: Why it Forms and how it Gives Rise to the Shape-memory Effect, OUP Oxford, 2003.

[23] T. Inamura, J.I. Kim, H.Y. Kim, H. Hosoda, K. Wakashima, S. Miyazaki. Composition dependent crystallography of $\alpha$ " -martensite in Ti-Nb-based $\beta$-titanium alloy, Philos Mag 87 (2007) 3325-3350.

[24] T. Inamura, Y. Yamamoto, H. Hosoda, H.Y. Kim, S. Miyazaki. Crystallographic orientation and stress-amplitude dependence of damping in the martensite phase in textured Ti-Nb-Al shape memory alloy, Acta Mater 58 (2010) 2535-2544.

[25] D.S. Lieberman, M.S. Wechsler, T.A. Read. Cubic to Orthorhombic Diffusionless Phase Change- Experimental and Theoretical Studies of AuCd, J Appl Phys 26 (1955) 473.

[26] N.B. D’yakonova, I.V. Lyasotskii, Y.L. Rodionov. Orthorhombic martensite and the $\omega$ phase in quenched and deformed titanium alloys with 20-24 at \% Nb, Russian Metallurgy (Metally) 2007 (2007) 51-58.

[27] S. Nambu, N. Shibuta, M. Ojima, J. Inoue, T. Koseki, H.K.D.H. Bhadeshia. In situ observations and crystallographic analysis of martensitic transformation in steel, Acta Mater 61 (2013) 4831-4839.

[28] Z. Nishiyama. Martensitic Transformation, Academic Press, 1973.

[29] Y. Soejima, S. Motomura, M. Mitsuhara, T. Inamura, M. Nishida. In situ scanning electron microscopy study of the thermoelastic martensitic transformation in Ti-Ni shape memory alloy, Acta Mater 103 (2016) 352-360. 
[30] J.W. Christian. The Theory of Transformations in Metals and Alloys, Elsevier Science, 2002. 


\section{Table caption}

Table 1

Habit plane orientation and shape-change direction of HVs. Lattice correspondence and the notations of habit plane variants are following our previous study [9].

\section{Figure captions}

Figure 1: Typical morphologies and the KC conditions of the HVCs in Ti-23Nb-3Al. " $V_{\text {I }}$ cluster" and " $V_{\text {II }}$ cluster" are formed with the junction plane corresponding to the $K_{1}$ plane of the $\{111\}_{0}$ type I twin and the $<211>_{0}$ type II twin, respectively. The rotation angles for $\mathrm{KC}$ condition at junction plane $(\mathbf{Q})$ are $0.69^{\circ}$ and $0.57^{\circ}$ for $\mathrm{V}_{\mathrm{I}}$ and $\mathrm{V}_{\mathrm{II}}$ clusters, respectively. Our previous study showed that rotation $\mathbf{Q}$ acted only in $\mathrm{V}_{\mathrm{I}}$ cluster and the junction plane of $\mathrm{V}_{\mathrm{II}}$ is incompatible [9].

Figure 2: Specimen preparation procedure. The specimen surface was flattened in parent phase and the surface relief by the forward transformation upon cooling was observed.

Figure 3: Habit plane traces and shape change directions of the HVs. This stereographic projection of $\boldsymbol{p}$ and $\boldsymbol{d}$ shows the geometry of martensite on the specimen surface observed in this study.

Figure 4: Differential interference contrast image of the specimen surface at (a) $308 \mathrm{~K}$, (b) $303 \mathrm{~K}$, (c) $298 \mathrm{~K}$, (d) $288 \mathrm{~K}$ and (e) $223 \mathrm{~K}$, and (f) the number of identified HVCs at each temperature range. Most of the HVs formed pairs. Note that only $V_{I}$ clusters appeared in the early stage of the transformation.

Figure 5: Number of identified HVCs below $M_{\mathrm{f}}$. Undetected HVs would have habit planes nearly parallel to the surface normal or shape change directions almost perpendicular to the surface normal.

Figure 6: Formation of a $\mathrm{V}_{\mathrm{I}}$ cluster by (a) paired nucleation, (b) branching and (c) collision. The $80 \%$ of the $\mathrm{V}_{\mathrm{I}}$ cluster is formed by the paired nucleation or branching in which the junction plane corresponds to the nucleation site of the relevant $\mathrm{HV}(\mathrm{s})$.

Figure 7: Formation sequence of a $\mathrm{T}$ cluster. $\mathrm{T}$ cluster is formed from a $\mathrm{V}_{\mathrm{I}}$ cluster and is a derivative of the $\mathrm{V}_{\mathrm{I}}$ cluster. 
Figure 8: Formation of $\mathrm{V}_{\text {II }}$ clusters by (a) collision and (b) reflection. Note that paired nucleation and branching, which were commonly observed modes for forming $\mathrm{V}_{\mathrm{I}}$ clusters, were never observed for formation of a $\mathrm{V}_{\text {II }}$ cluster.

Figure 9: Number of $\mathrm{V}_{\mathrm{I}}$ (upper) and $\mathrm{V}_{\text {II }}$ (lower) clusters formed by each mode of formation at each temperature range. Only $V_{I}$ formed in the early stage of the transformation ( $308 \mathrm{~K}$ to $303 \mathrm{~K}$ ). The martensite plate or HVC that appears just below $M_{\mathrm{S}}$ has the lowest energy barrier to its nucleation and growth in general. Therefore, $\mathrm{V}_{\mathrm{I}}$ cluster was determined to be more energetically favored than the $\mathrm{V}_{\text {II }}$ cluster.

Figure 10: Fraction of the $\mathrm{V}_{\mathrm{I}}$ (left) and $\mathrm{V}_{\mathrm{II}}$ (right) clusters formed by each formation mode after the completion of the transformation. The fraction of $\mathrm{V}_{\mathrm{I}}$ by paired nucleation and branching matches the fraction of the $\mathrm{V}_{\mathrm{I}}$ clusters containing compatible junction planes. On the other hand, more than $50 \%$ of the $\mathrm{V}_{\mathrm{II}}$ clusters were formed by collisions, and this value approximately corresponds to the fraction of $\mathrm{V}_{\mathrm{II}}$ clusters containing incompatible junction planes.

Figure 11: Schematic diagrams of the relationship between the formation mode and the location of the incompatibility. The formation of $\mathrm{V}_{\mathrm{I}}$ clusters by paired nucleation or branching requires the $\{111\}_{0}$ type I twin relationship to be exactly held. The junction plane formed by collision becomes incompatible. 


\begin{tabular}{cccccc}
\hline HV & $\mathbf{p}$ & $\mathbf{d}$ & HV & p & d \\
\hline $1(+)$ & $(-\mathrm{h}, \mathrm{k}, \mathrm{k})$ & {$[\mathrm{u}, \mathrm{v}, \mathrm{v}]$} & $4(+)$ & $(\mathrm{k}, \mathrm{h},-\mathrm{k})$ & {$[\mathrm{v},-\mathrm{u},-\mathrm{v}]$} \\
$1(-)$ & $(\mathrm{h}, \mathrm{k}, \mathrm{k})$ & {$[-\mathrm{u}, \mathrm{v}, \mathrm{v}]$} & $4(-)$ & $(-\mathrm{k}, \mathrm{h}, \mathrm{k})$ & {$[-\mathrm{v},-\mathrm{u}, \mathrm{v}]$} \\
$2(+)$ & $(\mathrm{h}, \mathrm{k},-\mathrm{k})$ & {$[-\mathrm{u}, \mathrm{v},-\mathrm{v}]$} & $5(+)$ & $(\mathrm{k}, \mathrm{k},-\mathrm{h})$ & {$[\mathrm{v}, \mathrm{v}, \mathrm{u}]$} \\
$2(-)$ & $(\mathrm{h},-\mathrm{k}, \mathrm{k})$ & {$[-\mathrm{u},-\mathrm{v}, \mathrm{v}]$} & $5(-)$ & $(\mathrm{k}, \mathrm{k}, \mathrm{h})$ & {$[\mathrm{v}, \mathrm{v},-\mathrm{u}]$} \\
$3(+)$ & $(\mathrm{k},-\mathrm{h}, \mathrm{k})$ & {$[\mathrm{v}, \mathrm{u}, \mathrm{v}]$} & $6(+)$ & $(\mathrm{k},-\mathrm{k}, \mathrm{h})$ & {$[\mathrm{v},-\mathrm{v},-\mathrm{u}]$} \\
$3(-)$ & $(\mathrm{k}, \mathrm{h}, \mathrm{k})$ & {$[\mathrm{v},-\mathrm{u}, \mathrm{v}]$} & $6(-)$ & $(-\mathrm{k}, \mathrm{k}, \mathrm{h})$ & {$[-\mathrm{v}, \mathrm{v},-\mathrm{u}]$} \\
\hline \multicolumn{5}{c}{$\mathrm{h}=0.705115, \mathrm{k}=0.501405, \mathrm{u}=0.0488206, \mathrm{v}=0.0324642$}
\end{tabular}

\section{Table 1}


$\mathrm{V}_{\text {I }}$ cluster $\mathbf{Q}: 0.69^{\circ}$
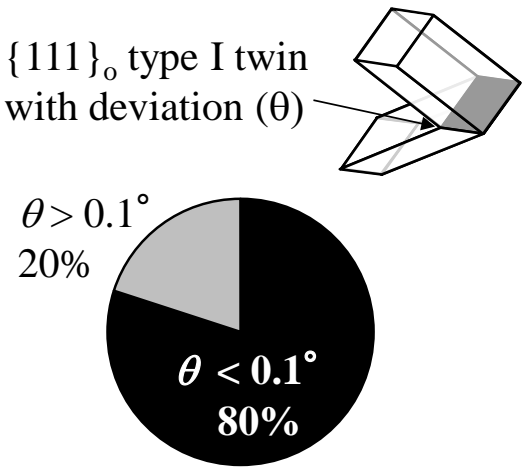

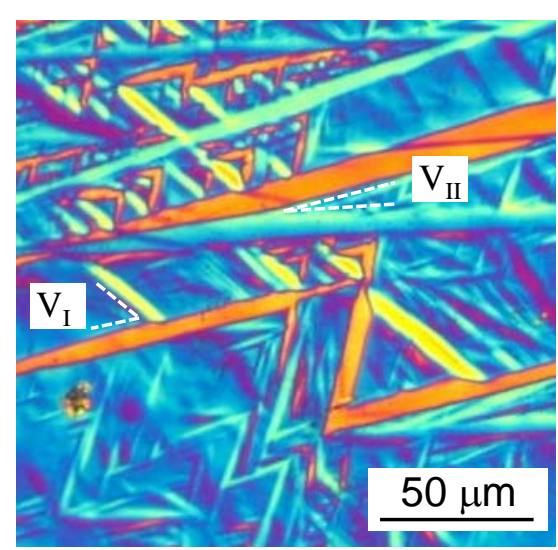

$\mathrm{V}_{\mathrm{II}}$ cluster $\mathbf{Q}: 0.57^{\circ}$
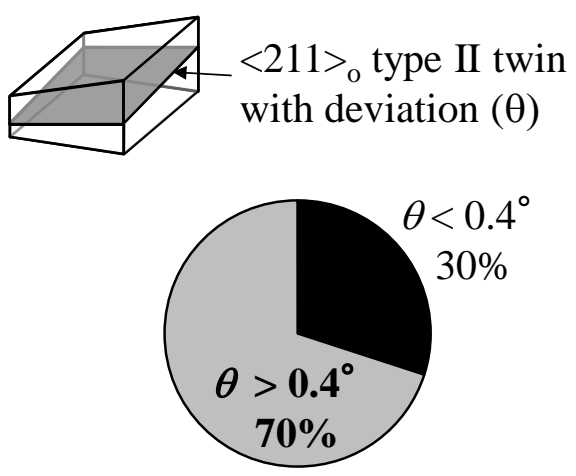

Figure 1 

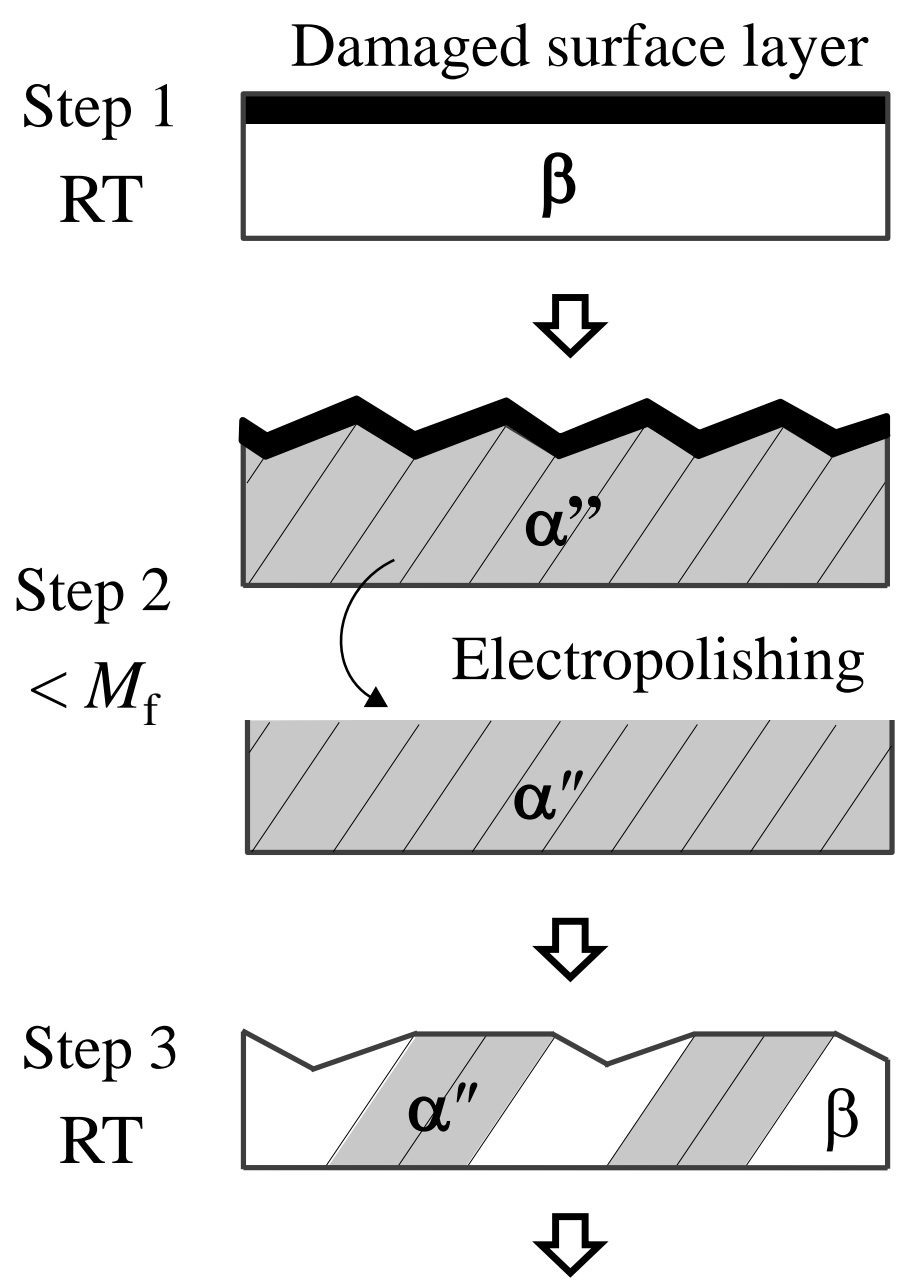

Plasma etching

Step 4

$>A_{\mathrm{f}}$

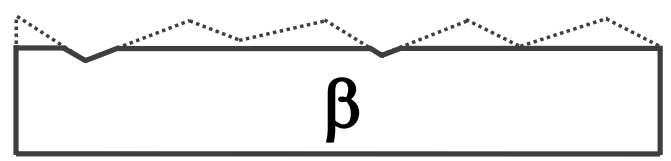

Figure 2 


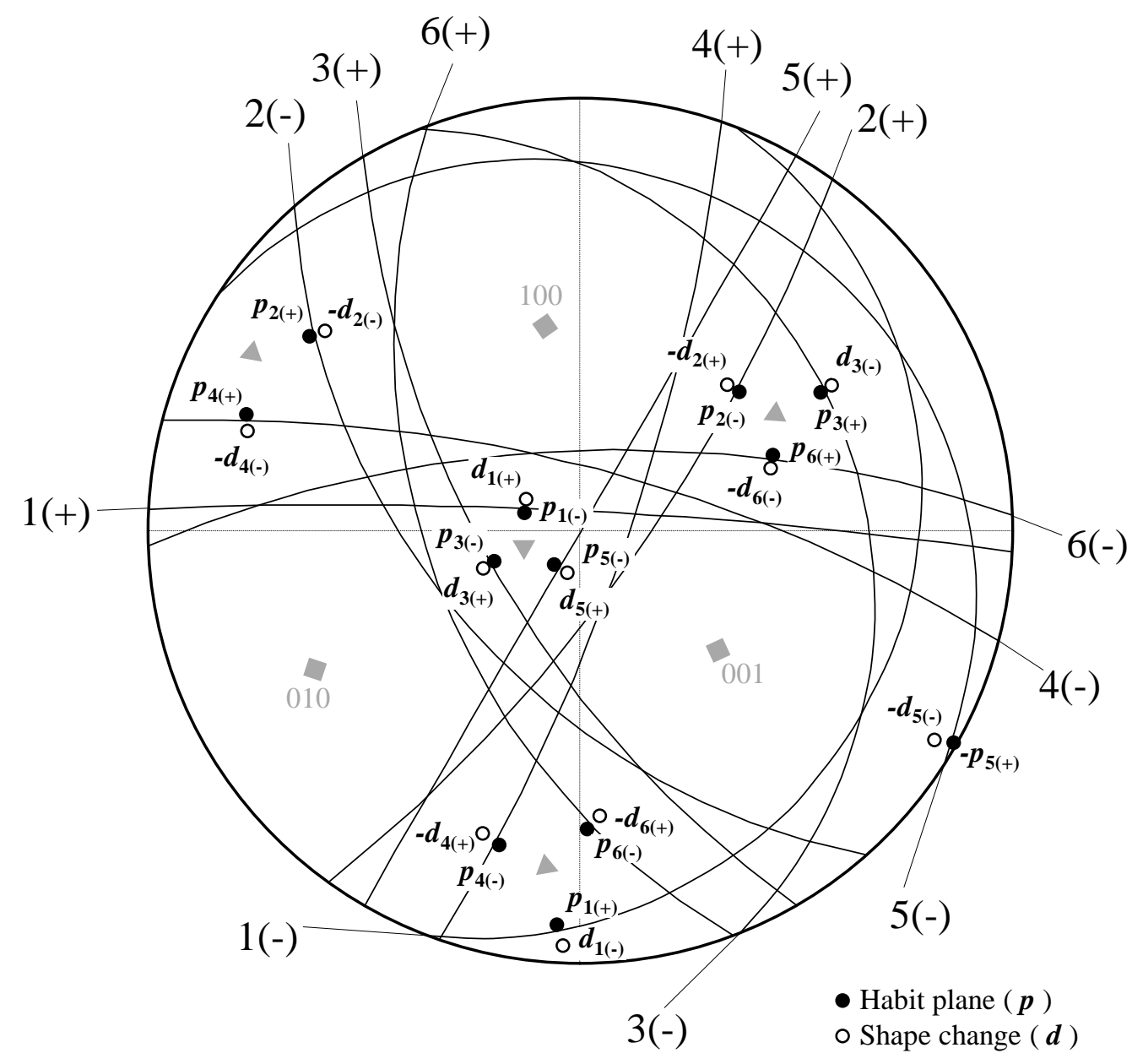

Figure 3 

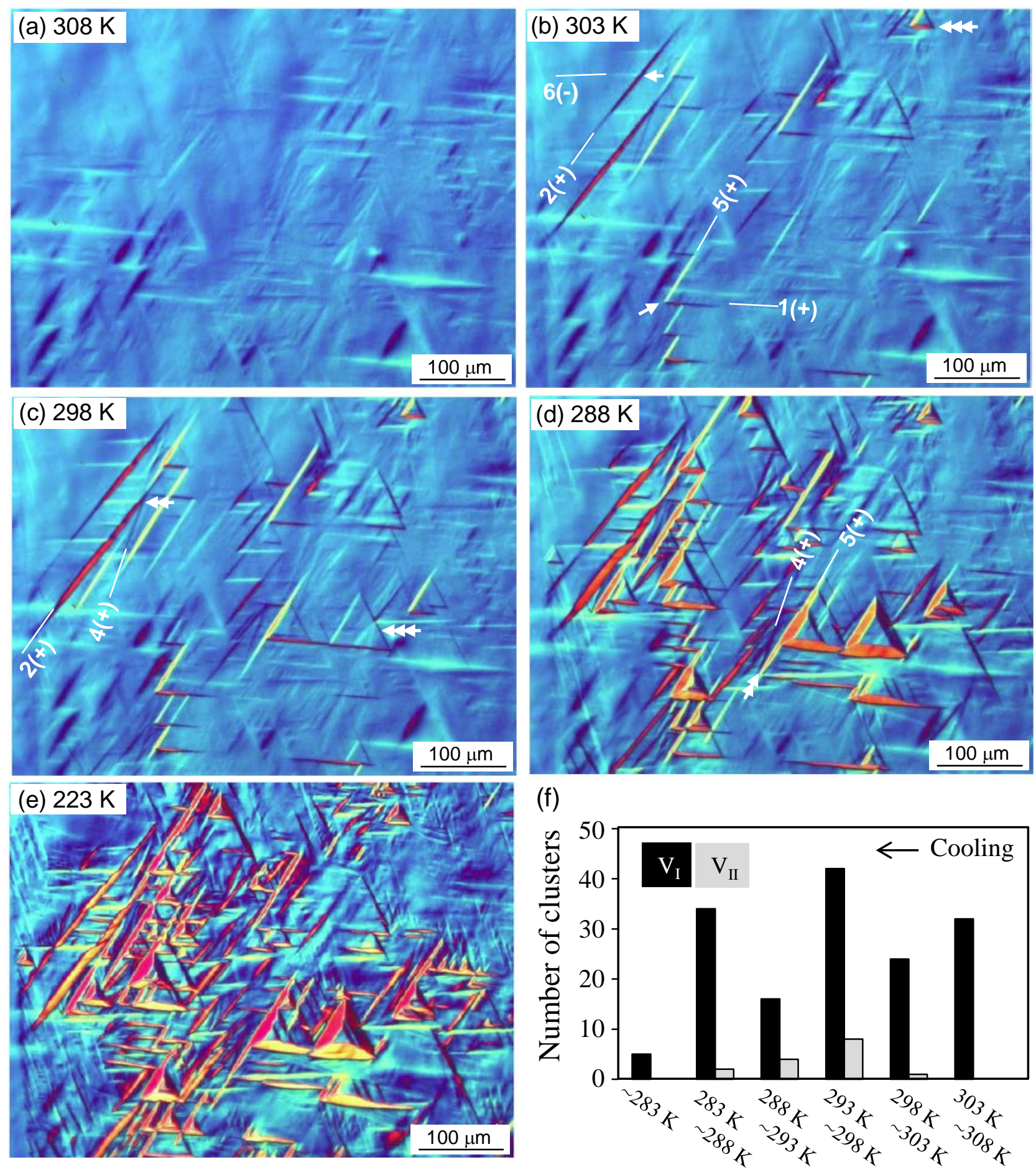

Figure 4 


\begin{tabular}{|l|l|l|l|l|l|l|l|l|l|l|l|l|}
\hline & $1(+)$ & $1(-)$ & $2(+)$ & $2(-)$ & $3(+)$ & $3(-)$ & $4(+)$ & $4(-)$ & $5(+)$ & $5(-)$ & $6(+)$ & $6(-)$ \\
\hline $1(+)$ & - & & & & 28 & & & & 48 & & & 4 \\
\hline $1(-)$ & & - & & & & & & & & & & \\
\hline $2(+)$ & & & - & & & & 3 & & 6 & & & 35 \\
\hline $2(-)$ & & & & - & & & & & & & & \\
\hline $3(+)$ & 28 & & & & - & & & & 24 & & & \\
\hline $3(-)$ & & & & & & - & & & & & & \\
\hline $4(+)$ & & & 3 & & & & - & & 2 & & & \\
\hline $4(-)$ & & & & & & & & - & & & & \\
\hline $5(+)$ & 48 & & 6 & & 24 & & 2 & & - & & & \\
\hline $5(-)$ & & & & & & & & & & - & & \\
\hline $6(+)$ & & & & & & & & & & & - & \\
\hline $6(-)$ & 4 & & 35 & & & & & & & & & - \\
\hline
\end{tabular}

Figure 5 
(a) Paired nucleation

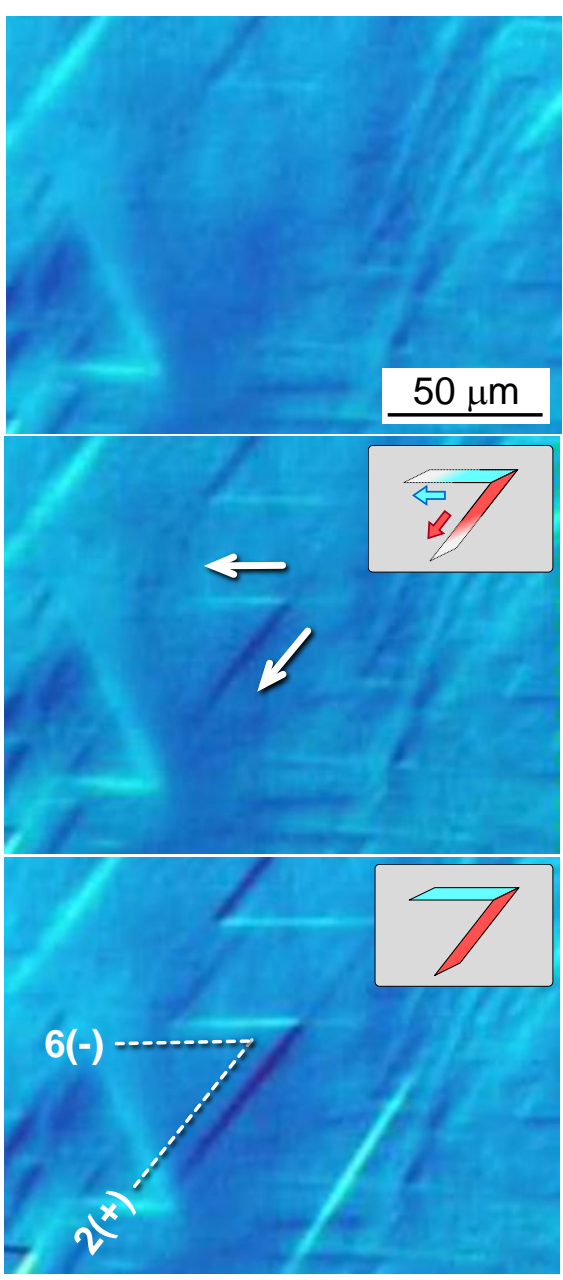

(b) Branching

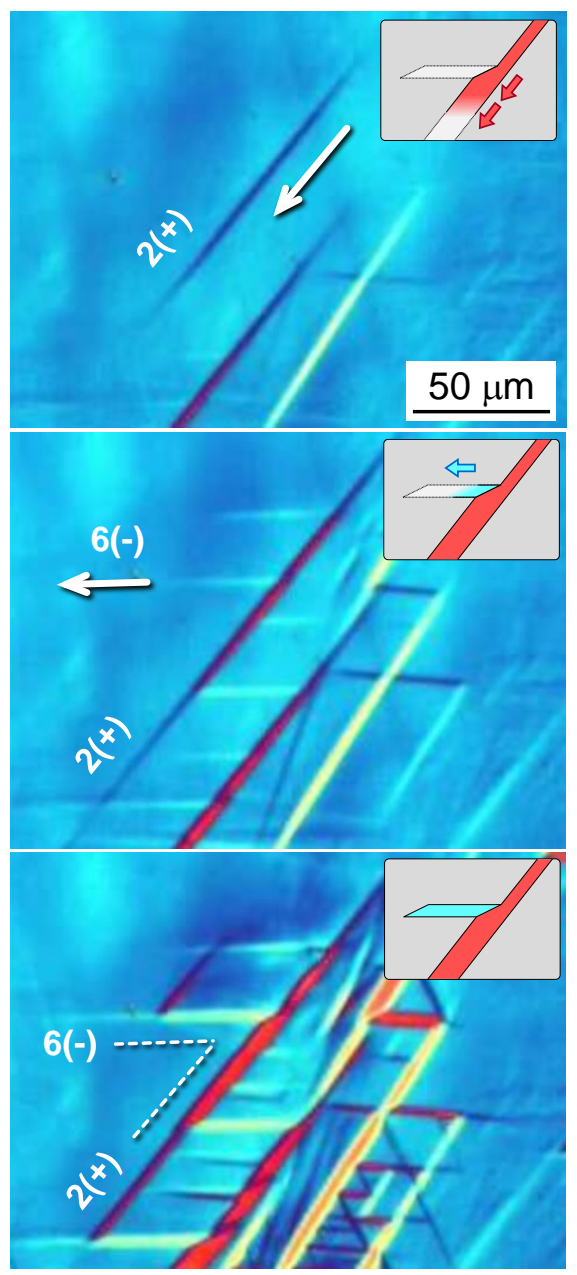

(c) Collision

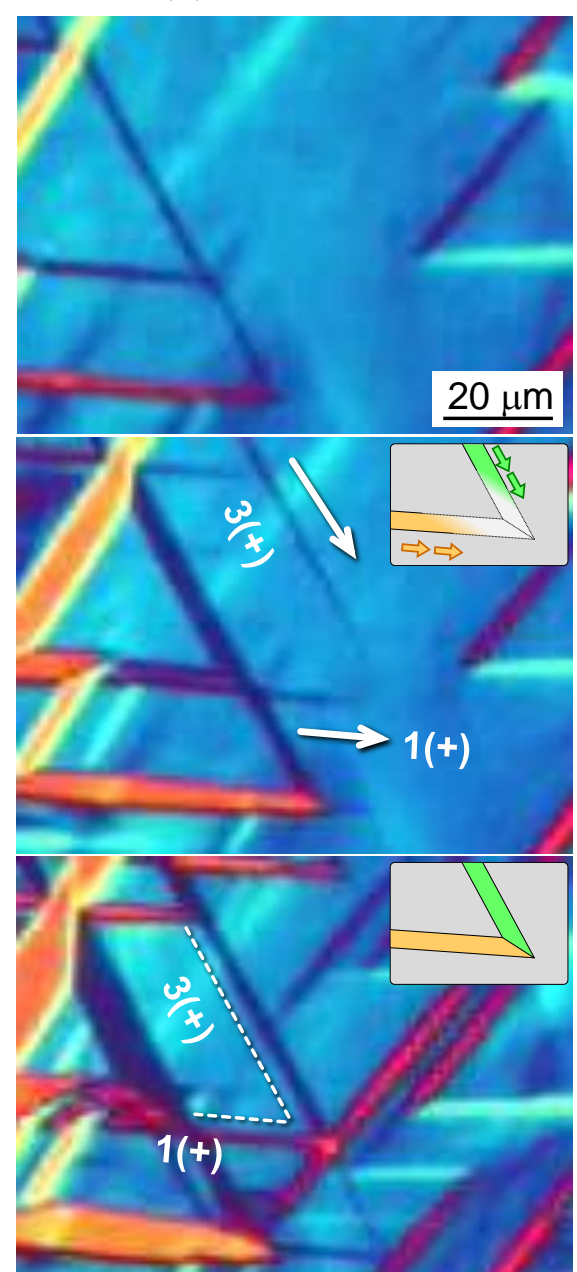

Figure 6 


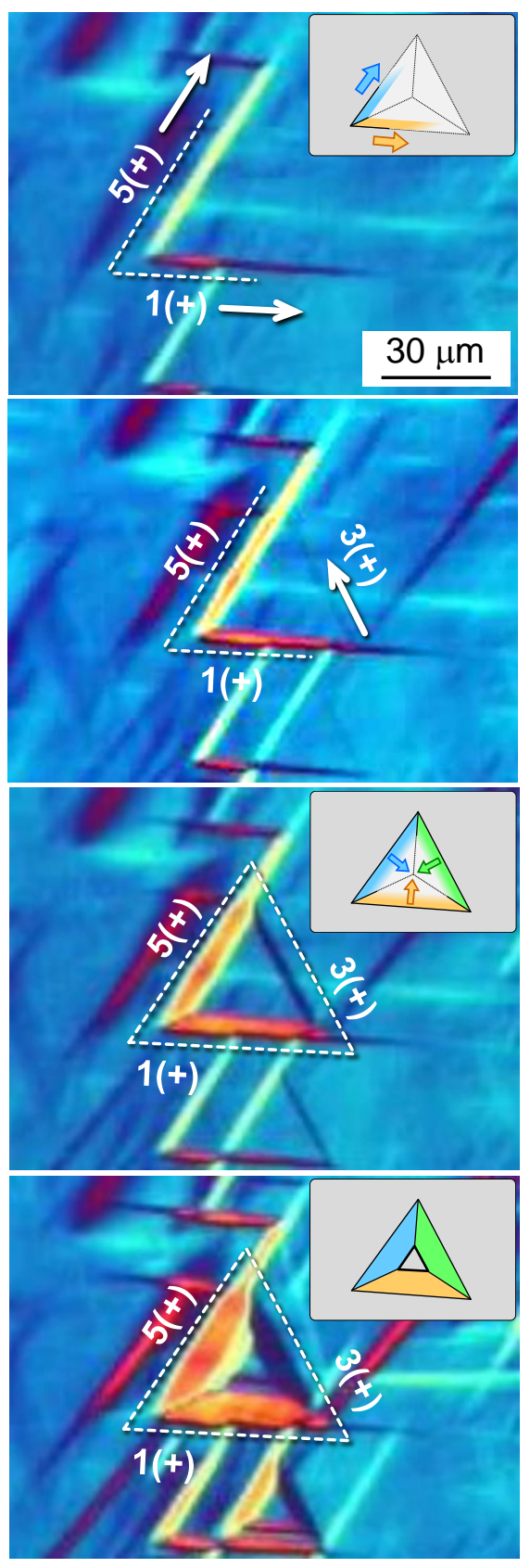

Figure 7 
(a) Collision

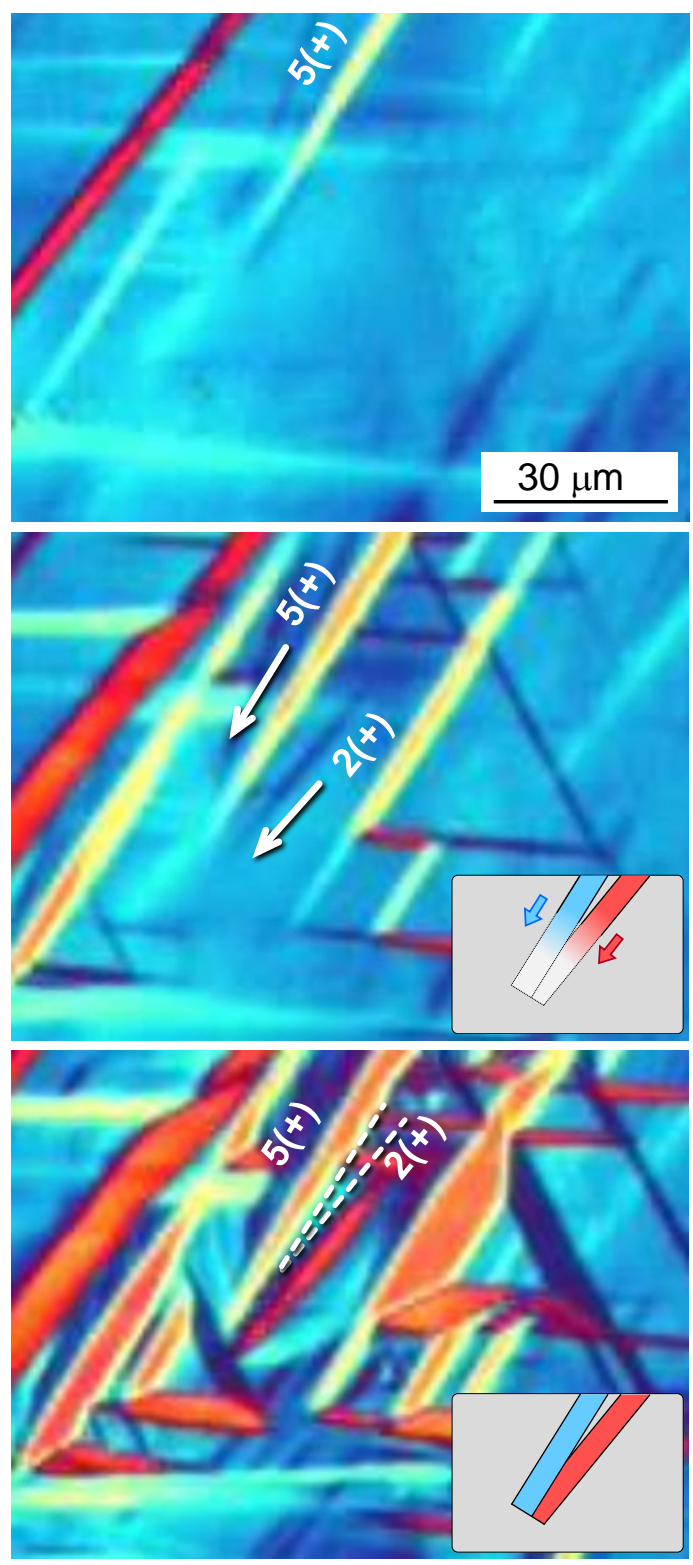

(b) Reflection
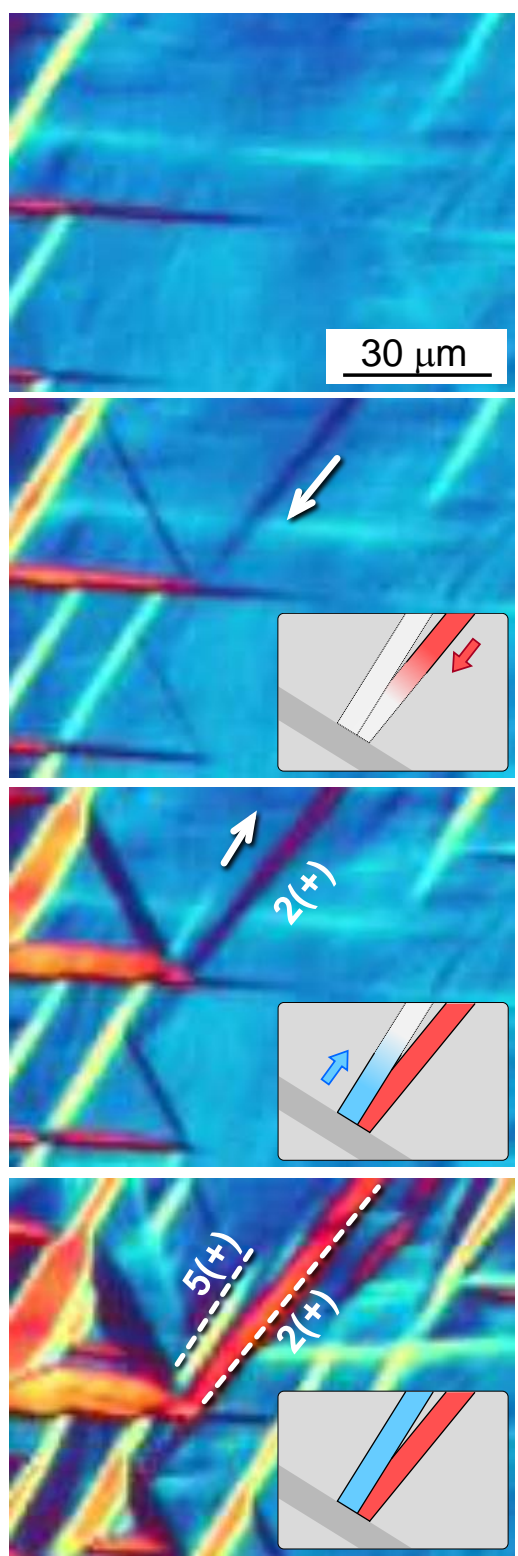

Figure 8 


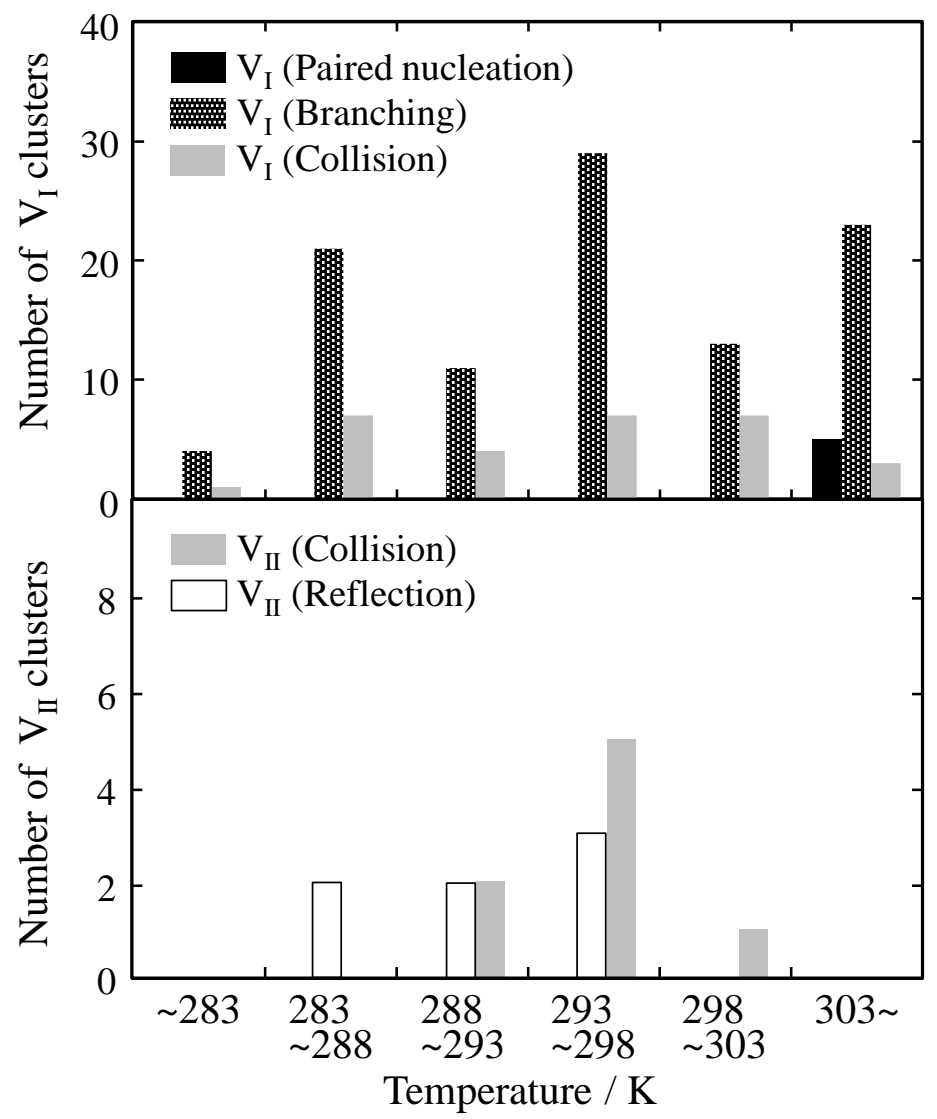

Figure 9 

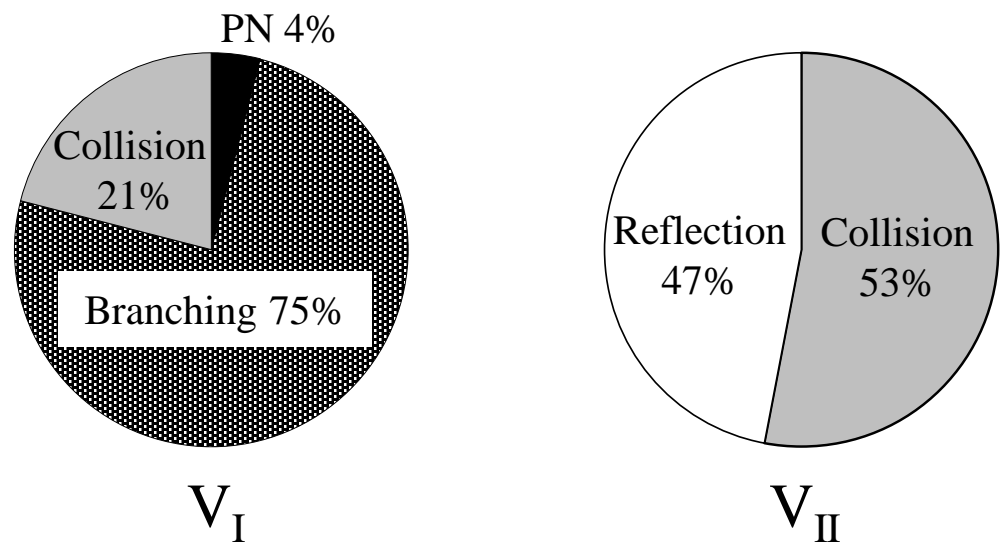

Figure 10 
$\{111\}_{0}$ type I twin OR without deviation from $\mathrm{KC}$

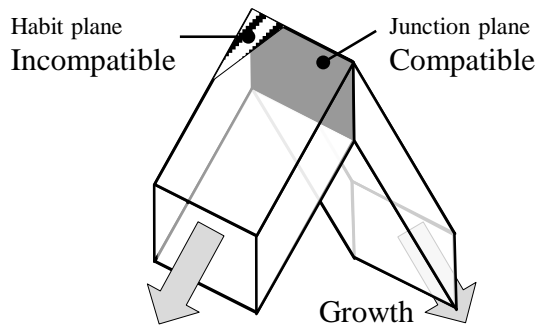

Paired nucleation or branching
$<211>$ type II and $\{111\}_{0}$ type I twin OR with deviations from KC

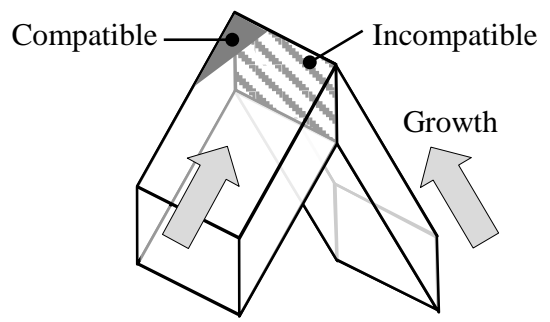

Collision 
(a) Paired nucleation

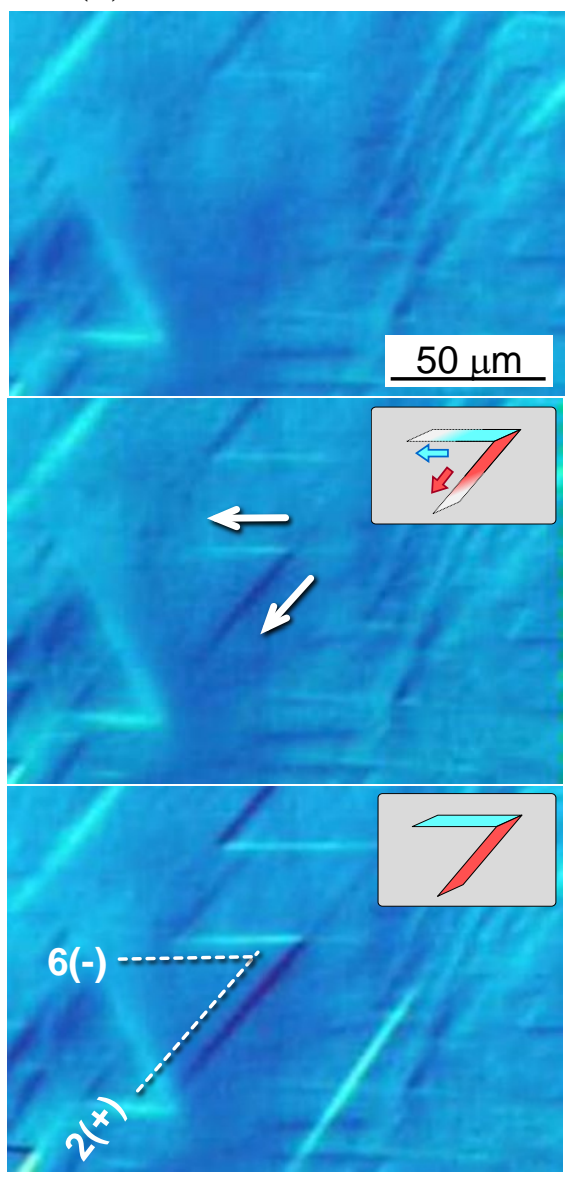

(b) Branching

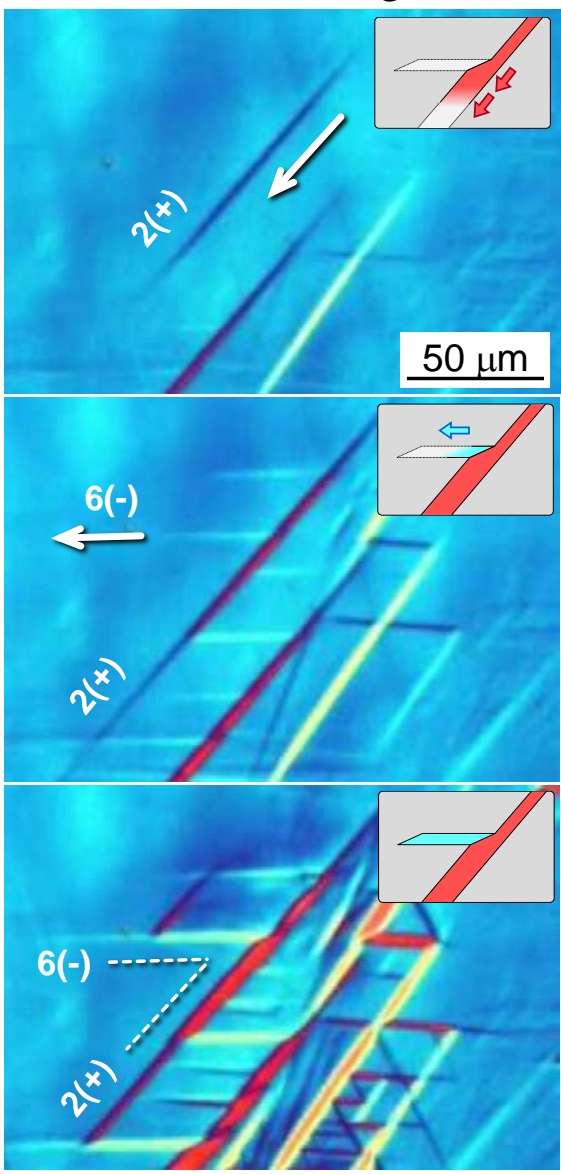

(c) Collision

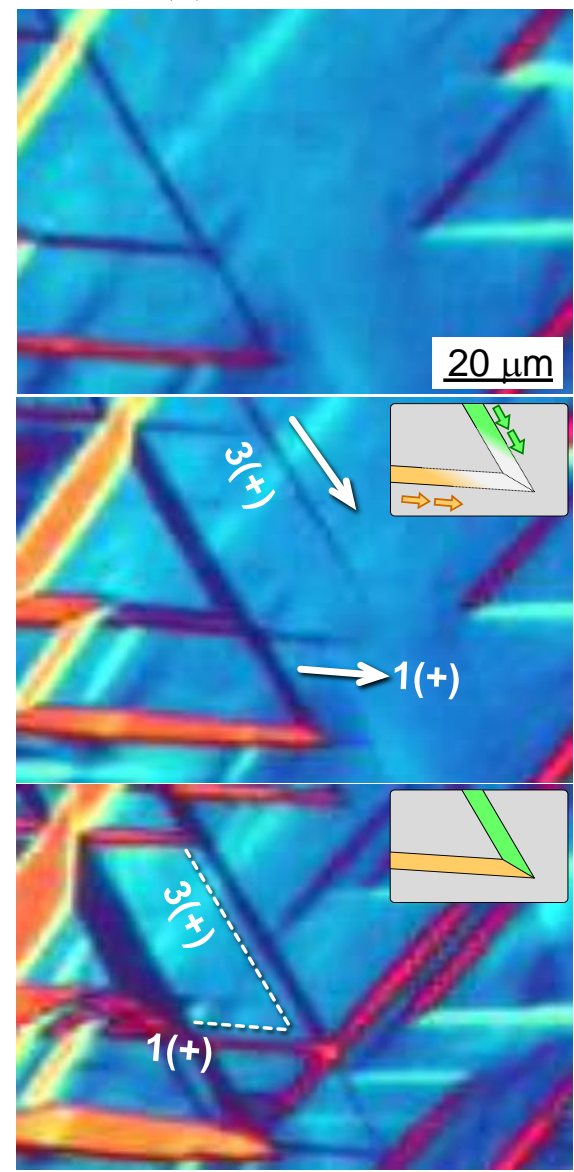

The $80 \%$ of the $\mathrm{V}_{\mathrm{I}}$ cluster is formed by the paired nucleation or branching in which the junction plane corresponds to the nucleation site of the relevant $\mathrm{HV}(\mathrm{s})$. In contrast, $\mathrm{V}_{\mathrm{II}}$ cluster is originated to the collision of HVs. No paired nucleation and branching were observed for $\mathrm{V}_{\mathrm{II}}$. There is a strong tendency to form $\mathrm{V}_{\mathrm{I}}$ rather than $\mathrm{V}_{\mathrm{II}}$ in the nucleation and is not fully explained by the evaluation of KC conditions. 